\title{
SOCIETY'S GREETINGS TO MRS - EUROPE
}

IRepresenting the MRS at the recent meeting of materials scientists in France was First Vice President C.W. White of Oak Ridge National Laboratory. His introductory remarks are reprinted here.]

It is a pleasure for me to attend this conference, both as a scientist and as the representative of the Materials Research Society. The topic chosen for the conference is something that has been of interest to me for the past five years, and the technical content of the meeting appears to be excellent. I commend the Organizing Committee and the Local Arrangements Committee for the work they have done in presenting such a superior technical meeting in so beautiful a location.

In my capacity as an officer of the Society it is a special privilege to attend this meeting. The Society is pleased to co-sponsor the conference. As most of you are well aware, the Materials Research Society is an international professional organization uniting the worldwide community of scientists and engineers involved with materials. Scientists from Europe have played a very important role in the evolution of the MRS, and the group's ties to Europe are very strong. Indeed, of the 25 nations represented among the Society's membership, 16 are European. Fifteen percent of total membership is from Europe. Both of the other conferences the MRS has sponsored outside the United States have been held in Europe: a session on nuclear waste management in Berlin last summer, and a meeting on phase transformations in solids in Crete this summer. The proceedings of both of these conferences are included among the Society's Conference Proceedings Series.

The interest in materials science is worldwide. It is not limited by national, regional or geographical boundaries. The Society encourages the further development of an international organization. This will increase communication among those working in the field, increase collaboration and help in the achievement of common goals. In addition to the sponsorship of meetings in Europe, the Society is helping to foster publication of the new journal, Materials Letters, which is published here and several of whose MRSappointed Associate Editors are Europeans.

The goal of the Materials Research Society is to provide a forum for the dissemination of information on topics on the frontier of materials science. To fulfill this objective we encourage the

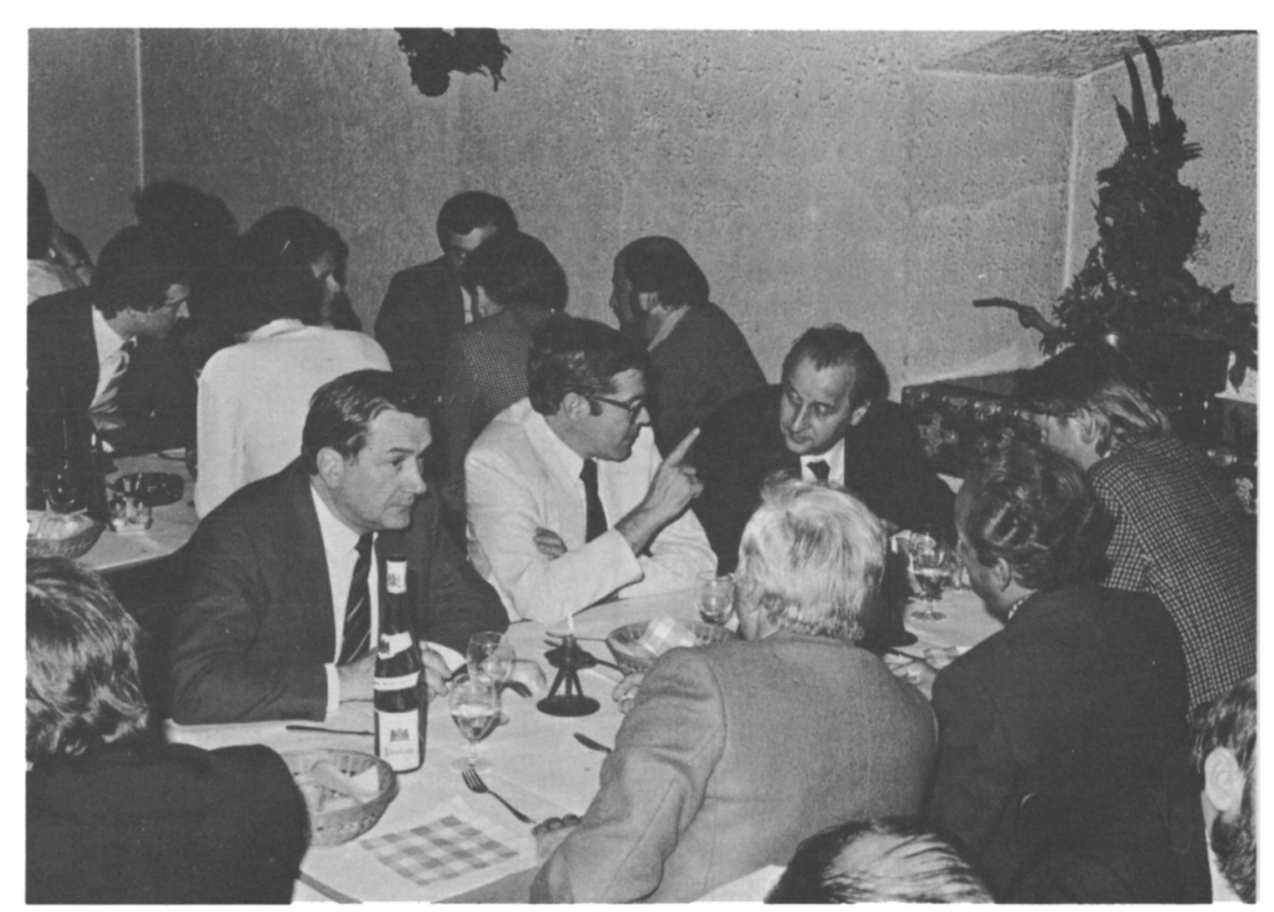

SERIOUS DISCUSSIONS about the future of MRS - Europe dominate the table at the conference banquet as Woody White (pointing) expresses the Society's strong interest in fostering a successful European affiliate formation of affiliated societies with similar objectives. Particularly, we want to encourage the development of a strong MRS - Europe closely aligned with our own international Society. There are many common benefits that can be shared through such an affiliation. The formation and development of a strong MRS - Europe with meetings organized and conducted by our colleagues here is entirely consistent with our objectives. We would hope that MRS - Europe would continue to meet in future years and that the scope of future meetings would be expanded to include other topics in the forefront of materials research.

In closing, let me again thank you for the invitation to attend this conference; which promises to be very interesting and informative. 